\title{
Evaluating the effectiveness of ergonomics application
}

\author{
Ugbebor J. $\mathrm{N}^{1}$ and Adaramola S. $\mathrm{S}^{2}$. \\ ${ }^{1}$ University of Port Harcourt, Nigeria E-mail;johnugbebor@yahoo.com \\ ${ }^{2}$ Vine Tribometric Consultant, P.H, Nigeria E-mail:vinetribo@yahoo.com
}

\begin{abstract}
The effectiveness of ergonomics application is achieved in the course of this research by reviewing ergonomics literature, internet searches and case studies of a number of work related musculoskeletal disorders (WMSD's) and other ergonomic related workplace incidence rate. The results of ergonomic intervention control measures such as engineering controls, administrative controls and personnel protective equipment were also studied. The findings in this paper may help to development model for analysing and solving ergonomic problems in the workplace. It concludes on the need for management to support ergonomics intervention programme for effective cost saving, litigation avoidance and better productivity.
\end{abstract}

Keywords: Risk Factors, Intervention, Management Review and Control Measure.

\section{Introduction}

Ergonomic application in organisations such as offshore or onshore facilities, downstream, manufacturing and construction companies may cover many grounds. An assessment of the effectiveness of ergonomics application for improving workers comfort and deliverability is a central focus of this paper. The studies have concluded that evaluating the program from the perspective of those it intended to serve can provide solutions across the upstream, downstream, manufacturing and construction industries, an important insight into changes that are not otherwise easy to observe or measure : Vink and kompler; (2) Aaras and others (1), Ekbergt 3).

\section{Ergonomic Program Successes}

The study indicated that for ergonomic programme to succeed, it requires an effective implementation of ergonomic management system with emphasis on managing ergonomic risk in organisations activities, to assure zero or minimum injuries to personnel and better job performance. Key elements of an ergonomics management system include strong management support, policy guidelines, proper organisations, responsibility,

resource, standard and documentation, hazard and effect management process (HEMP), effective planning and procedure, implementation and monitoring, audit and corrective action and management review.

The study reveals that top management support to ergonomic programme change supervisors to proactiveness in addressing employees concerns for ergonomic problems, staff training, ergonomics indoctrination. Regular evaluation of the effectiveness of ergonomic changes and cost benefit analysis of ergonomic interventions will lead to reduced absenteeism due to WMSD's (work related musculoskeletal disorders), increase productivity, better quality and turnover.

In the workplace research has indicated that the effects of work related musculoskeletal disorders (WMSD's) may include health effects and economic effects. The health effects such as repeated 
biomedical stress and micro trauma which can cause or aggravate work related musculoskeletal disorders to painful, debilitating state involving muscles, tendons, tendon sheaths and nerves (5). On the other hand, economic effects of WMSD's may include some direct cost like medical bills, compensation, and litigation costs. While the indirect cost may include damage morals resulting in low job output, human error, discomfit, industrial relations challenges and poor quality resulting from mistakes.

\section{Occupational Risk Factors.}

Research identifies that the combined effects of several occupational risk factors in a job will lead to high probability of causing WMSD's. These work related risk factors may include repetitive motion injuries (especially during prolonged activities) awkward postures, excessive bending or twisting, forceful exertions continued elbow or shoulder elevation (e.g. over health work), excessive use of small muscle, vibration, restrictive workstations, (e.g., inadequate clearances) improper seating or support, inappropriate hand tools, extreme temperatures, annoying noise, exposure to hazard, poor lighting and occupational psychosocial factors (job stress, Ergonomic program, 2003)

\section{Problem solving in ergonomics evaluation}

The research indicated that to solve the work related ergonomics problems the following steps must be taken;

a) Identifying existing and potential WMSD's and associated factor, through work place analyses.

b) Define the problems and set priorities for abatement of identified WMSD's

c) Gather information (through direct observation, videotaping, checklist, one - on - one interview and company records etc).

d) Assess the problem (by establishing their relative importance and need for any action).

e) Control the problem (this may involve implementation of ergonomics intervention programmes like hardware changes, redesigning of work stations, change of methods of doing the work, training etc)

f) Install the new system. g) Evaluating the effectiveness of the change or corrective actions and documenting the results.

\section{Methodology of studies}

\subsection{Problem identification in case study organization.}

The study analyses data from five companies. The data was collated from safety records (SR), medical records(MR) health hazard inventory reports (HHIR)and work force report(WFR). The methodology for the study includes questionnaire and surveys, observation, incident records, cases referrals records.

The following comparative results were gathered from the five companies all in the oil and gas sector. Incidence comparative records allow monitoring of changes overtime and performance.

Table 1

$\%$ of Ergonomics Related Illness compared with Recorded Diseases in 2009 of Five Companies

\begin{tabular}{|l|l|l|l|l|l|}
\hline Companies & A & B & C & D & E \\
\hline S.R & 15 & 45 & 12 & 34 & 65 \\
\hline M.R & 18 & 16 & 67 & 14 & 13 \\
\hline H.H.I.R & 25 & 23 & 45 & 24 & 25 \\
\hline W.F.R & 45 & 15 & 54 & 25 & 14 \\
\hline
\end{tabular}

\section{Some useful tools for detail analysis}

To further evaluate those jobs or worksite having WMSD's risk factors the follow systematic steps were considered;

a) Find on the degree of WMSD risk, look for trend (e.g. age, gender, work task and time of injury)

b) Identify the work task with risk factors

c) Identify both problems and solutions, development checklists, conducts consequence analysis, and report findings

\section{Recommendation.}

This research recommends a three step ergonomic risk factor prevention and control 


\subsection{Engineering Control}

The primary method of preventing and controlling exposure to WMSD's hazards is through effective design or redesigning of job or workstation to fit the limitations and capabilities of workers. This offers permanent solutions to ergonomic problems.

\subsection{Substitutions}

Another effective method of eliminating the hazard is by substitution of a particular tool for another more effective one which can allow for neutral posture.

\subsection{Work Practises.}

This involves changing work techniques and regularly monitoring them. Regular maintenance, adjustment and modification of equipment and tools that encourage correct posture use of proper body mechanics, correct use of equipment and workstations are recommended

\subsection{Administrative Controls}

These include reduction of duration of work frequency and severity of exposure to WMSD's hazards. Some examples of administrative control include reducing repetitive motions, limiting overtime work, increasing number of personnel assigned to a task, institute job rotation, introduce sufficient break, training good work scheduling and work practices.

\subsection{PPE's}

The research also recommends that PPE's should be properly worn and used in accordance with manufacturers specifications; it should be available and accommodate the physical requirement of workers.

\subsection{Communication and Coordination}

This assures ergonomics intervention is appropriate and tailored for the worksite.

\subsection{Worksites Follow up}

Follow up ensure that all corrective action are implemented and monitored.

\section{References.}

[1] Aaras, A. et al., "Musculoskeletal, visual and Psychosocial Stress in VDU operators before and after multidisciplinary Ergo

[2] Adaramola, S. S. (2003); Ergonomic series a lecture note for Msc programme in occupational health and safety. Institute of Petroleum studies, university of Port Harcourt, Rivers State, Nigeria Pages 5 to $16-17$.

[3] Ekbert, K."Workplace Changes in successful rehabilitation". Journal of occupational rehabilitation. 5(1995): $253-269$

[4] Hudson, 2003, USA Army Ergonomic program.

[5] Isaac, S. and W. Michael. Handbook in Research and evaluation. $2^{\text {nd }}$ ed. San Diego: Edits Publishers, 1981.

[6] Medical services Ergonomics Programme, Headquarters, Department of Army, Washington DC, 15 August, 2003 DA PAM 40 - 21 page $1-12$.

[7] National Institute for Occupational Safety (NIOSH). "Elements of Ergonomics Programs". A primer based on workplace evaluations of musculoskeletal disorders. "Washington, DC:NIOSH, 1997".

[8] Oxenburgh, M., 1991, Increasing Productivity and Profit Through Health and Safety. Sydney: $\mathrm{CCH}$ Australia.

[9] Spilling, S., Eiteheim, J. and Aaras, A., 1986, Cost-benefit analysis of work environment investment at STK's telephone plant at Kongsvinger. In Corlett, N., Wilsin, J. and Manenica, I. (Eds), The Ergonomics of working Postures. London: Taylor \& Francis, 380 - 397.

[10] Tiraboschi et al., Jan 2002: Evaluating the effectiveness of an office ergonomics program.

[11] Ugbebor, J. N. (2004): Comparative Evaluation of Health, Safety and Environment (HSE) performance of some oil producing companies in the Niger Delta Region of Nigeria. A project submitted in partial fulfilment for the award of Degree of master of Engineering. Environmental Engineering in University of Port Harcourt, P 14, 39.

[12] Vink, P and M Kompier (1997); improving office work: a participatory Ergonomic Experiment in a naturalistic settling. Ergonomics 40, page $435-440$.

[13] West lander, C and others (1995); Evaluation of an Ergonomics intervention Programme in VOT workplace" Applied Ergonomics 26, 83. 